OPEN ACCESS

Edited by: Andreas Stengel,

Charité Universitätsmedizin

Berlin, Germany

Reviewed by:

Tobias Hofmann,

Charité Universitätsmedizin

Berlin, Germany

Meera Balasubramaniam, NYU Langone Medical Center,

Unites States

*Correspondence:

Michael Noll-Hussong

minohu@gmx.net

Specialty section:

This article was submitted to

Psychosomatic Medicine,

a section of the journal

Frontiers in Psychiatry

Received: 11 July 2017 Accepted: 29 November 2017 Published: 13 December 2017

Citation:

Gerdau I, Kizilhan JI and NollHussong M (2017) Posttraumatic

Stress Disorder and Related Disorders among Female Yazidi

Refugees following Islamic State of

Iraq and Syria Attacks - A Case

Series and Mini-Review.

Front. Psychiatry 8:282.

doi: 10.3389/fpsyt.2017.00282

\section{Posttraumatic Stress Disorder and Related Disorders among Female Yazidi Refugees following Islamic State of Iraq and Syria Attacks - A Case Series and Mini-Review}

\author{
Inga Gerdau', Jan Ilhan Kizilhan ${ }^{2}$ and Michael Noll-Hussong ${ }^{1 *}$ \\ ${ }^{1}$ Department of Psychosomatic Medicine and Psychotherapy, University of Ulm, Ulm, Germany, ${ }^{2}$ Duale Hochschule \\ Baden-Württemberg Villingen-Schwenningen, Villingen-Schwenningen, Germany
}

Following the severe attacks by the so-called "Islamic State of Iraq and Syria" on the Yazidi population, which started in summer 2014, the state government of BadenWürttemberg, Germany, funded a Special-Quota Project to bring 1,000 very ill or left-behind women and children who were being held hostage to 22 cities and towns in Baden-Württemberg to receive integrated care. Here, we report for the first time on the cases of four Yazidi women living in Ulm, Germany, focusing on the clinically observed and psychometrically assessed mental phenomena or disorders. Our primary aim was to explore what International Classification of Diseases, 10th Revision diagnoses are present in this population. Although highly traumatized, these women were suffering primarily from adjustment disorder rather than posttraumatic stress disorder according to official classification systems. Despite their symptoms of depression and anxiety, the women's responses to self-assessment questionnaires provided no evidence of compulsion, somatization, or eating disorders. The results suggest that further investigation of the individual-level effects of rape and torture, as well the historic, systemic, and collective effects, e.g., on families and societies, is required.

\section{Keywords: Yazidi, posttraumatic stress disorder, abuse history, mental disorders, somatic symptom disorder,} transcultural psychiatry

\section{BACKGROUND}

Psychiatric symptoms and mental disorders among refugees are recognized as an urgent problem $(1-5)$, especially in the Yazidi population $(6,7)$ after the severe attacks by the so-called "Islamic State of Iraq and Syria" (ISIS) in July $2014(8,9)$. Recently, it has been shown that about $43 \%$ of the victims of these attacks met the DSM-IV diagnostic criteria for posttraumatic stress disorder (PTSD), about $40 \%$ met the criteria for major depressive disorder (MD), and about $26 \%$ met the criteria for both disorders. A higher proportion of women than men suffered from PTSD and MD, and women with PTSD or depression were more likely than their male counterparts to report having experienced or witnessed the death of a spouse or child. Women with PTSD reported the core symptoms of PTSD (flashbacks, hypervigilance, and intense psychological distress due to reminders of trauma) more frequently than their male counterparts, and women tended to show undermodulation of emotions and low self-esteem in response to traumatic stress (10). Depressed 
women were more likely than their male counterparts to report feelings of guilt (11) or worthlessness (10). Severity of posttraumatic symptoms seems to be the strongest predictor of impaired health-related quality of life in PTSD outpatients (12). Until now there have been no published observational or clinical studies of the time course or long-term effects of these complex psychopathological phenomena and the associated risk and resilience factors (13-16) including cultural and anthropological factors (3), especially in the comparatively rare case of Yazidi patients given refuge in a "safe" Western country $(17,18)$.

We visited four Yazidi women (Table 1) who had been living in the city of Ulm, Germany since December 2015, as part of a specialquota project in the German region of Baden-Wuerttemberg that was designed to support some of the estimated 2,500 women and children who had been held hostage by ISIS (19). In Germany, they received permanent residence permit, psychological and social care and attended a language course. Initially, all the women were housed in an urban refugees' home for women with dependent children and were-where appropriate - offered the opportunity to take part in stabilizing, non-verbal, supportive art therapy. The impressions of the trained art therapist and other members of the caring staff were that the women presented in this case report needed psychosomatic support from our cooperating university clinic as they suffered badly from diverse physical, social, and psychological problems. Before being assigned to further treatment, all the women were reassessed to ensure that a valid, upto-date, clinical diagnosis was available and thus avoid causing further harm. A trained German, female psychotherapist (IG) carried out psychodiagnostic interviews (one to three sessions,
60 min each) in our outpatient clinic. A female translator accompanied the women to these interviews and assisted them, e.g., in responding to self-assessment questionnaires, as none of them spoke German or English and/or were unable to read at the time of the initial interviews (20).

To our methods: First, all women underwent preclinical, face-to-face examinations (one session, up to $90 \mathrm{~min}$, $60 \mathrm{~min}$ on average) by a Kurdish-German psychological psychotherapist (Jan Ilhan Kizilhan) who speaks Kurdish (Kurmanici) in conjunction with a psychometric screening in Northern Iraq (between March and December 2015) before they emigrated in December 2015. Approximately 6 months later, four of them underwent the abovementioned comprehensive clinical examination in Germany (completion: July 2016) to confirm preliminary diagnoses in accordance with established national standards before any therapeutic procedures were administered. The screening in Iraq comprised the ICD-10-Symptom-Rating $2.0(21,22)$, the Essen Trauma Inventory $(23,24)$, the Impact of Event Scale-Revised (25-27), and the Beck Depression Inventory II (BDI-II) (28-34) (Table 2). In Germany, they first underwent a standard medical examination (35) and then psychiatric assessment by a certified, supervised female psychotherapist using the Mini-International Neuropsychiatric Interview (German Version 6.0.0) (36) to give a general overview of current psychological state, the PTSD section of the structured clinical interview for DSM-IV (SCID-PTSD) $(37,38)$ to provide a more detailed picture of possible trauma symptoms and, once again, the BDI-II (Tables 2 and 3; Table S1 in Supplementary Material). The Global Assessment of Functioning, which yields a numeric score [0 (severely impaired)-100

TABLE 1 | Demographic and historical profiles of the Yazidi women.

\begin{tabular}{|c|c|c|c|c|c|c|c|c|c|}
\hline & $\begin{array}{l}\text { Age in years } \\
\text { in } 2015\end{array}$ & $\begin{array}{c}\text { Education } \\
\text { (years) }\end{array}$ & $\begin{array}{l}\text { Marital } \\
\text { status }\end{array}$ & $\begin{array}{l}\text { No. of } \\
\text { children }\end{array}$ & $\begin{array}{c}\text { Victim of sexual } \\
\text { violence }\end{array}$ & $\begin{array}{c}\text { Victim of physical } \\
\text { violence }\end{array}$ & Captivity & $\begin{array}{l}\text { Diseases } \\
\text { and injuries }\end{array}$ & $\begin{array}{l}\text { Suicidal } \\
\text { tendency }\end{array}$ \\
\hline$A$ & 45 & 8 & Married & 5 & No & Yes & Yes & Slipped disk & No \\
\hline $\mathrm{B}$ & 27 & 1 & Single & 0 & Yes & Yes & Yes & None & No \\
\hline C & 40 & 1 & Single & 0 & Yes & Yes & Yes & None & No \\
\hline $\mathrm{D}$ & 35 & None & Married & 9 & No & Yes & Yes & None & No \\
\hline
\end{tabular}

TABLE 2 | Summary of psychometric scores and diagnoses [International Classification of Diseases, 10th Revision (ICD-10)] received in 1 year.

\begin{tabular}{|c|c|c|c|c|c|c|c|c|c|}
\hline \multirow[t]{2}{*}{ Patients } & \multicolumn{4}{|c|}{ May 2015, Duhok, Iraq } & \multirow[b]{2}{*}{ ICD-10 (clinical exam) } & \multicolumn{4}{|c|}{ July 2016, Ulm, Germany } \\
\hline & $\mathrm{ETI}^{\mathrm{a}}$ & IES-R ${ }^{b}$ & ISR total score ${ }^{c}$ & BDI-II & & BDI-II & GAF & GARF & $\begin{array}{c}\text { ICD-10-GM (clinical } \\
\text { exam + M.I.N.I. + SCID-PTSD) }\end{array}$ \\
\hline A & 47 & 1.09 & 0.61 & 28 & F32.1, F43.1 (tentative diagnosis) & $10(\downarrow)$ & 55 & 78 & F42.23, Z60.5, Z63.4, Z73.3, Z91.4 \\
\hline $\mathrm{B}$ & 53 & 1.15 & 1.03 & 34 & F43.1 & $5(\downarrow)$ & 65 & 80 & F42.23, Z60.5, Z63.4, Z73.3, Z91.4 \\
\hline C & 50 & 0.39 & 1.02 & 24 & F43.1 & $1(\downarrow)$ & 61 & 76 & $\begin{array}{c}\text { F42.23, F43.8, T74.8, Z60.5, Z63.4, } \\
\text { Z73.3, Z91.4 }\end{array}$ \\
\hline D & 41 & -0.1 & 0.55 & 15 & F32.1, with traumatic symptoms & $20(\uparrow)$ & 48 & 71 & F42.23, Z60.5, Z63.4, Z73.3, Z91.4 \\
\hline
\end{tabular}

a-15: normal; 16-26: marginal, probable partial PTSD; >27: PTSD.

${ }^{b} \mathrm{x}>0$ indicates that $P T S D$ is very probable.

${ }^{\circ} \geq 0.6$ minimal symptoms; $\geq 0.9$ modest symptoms; $\geq 1.7$ severe symptoms.

¿0-13: minimal symptoms of depression; 14-19: mild symptoms of depression; 20-28: moderate symptoms of depression; 29-63: severe depression.

ETI, Essen Trauma Inventory; IES-R, Impact of Event Scale-Revised; ISR, ICD-10-Symptom-Rating; BDI-II, Beck Depression Inventory II; GAF, Global Assessment of Functioning; GARF, Global Assessment of Relational Functioning; PTSD, posttraumatic stress disorder; M.I.N.I., Mini-International Neuropsychiatric Interview.

ICD-10-GM-Codes: F42.23 = adjustment disorder with mixed anxiety and depression; F43.8 = other reactions to severe stress; T74.8 = abuse of a person not otherwise classified; Z60.5 = target of perceived adverse discrimination and persecution; Z63.4 = disappearance and death of family members; Z73.3 = stress, not otherwise classified; Z91.4 = other personal history of psychological trauma, not otherwise classified.

Severe symptoms are marked in red. 
TABLE 3 | ICD-10-Symptom-Rating (International Classification of Diseases, 10th Revision) subscale scores in May 2015, Iraq.

\begin{tabular}{|c|c|c|c|c|c|c|}
\hline & $\begin{array}{l}\text { Depressive } \\
\text { syndrome }^{\mathrm{a}}\end{array}$ & $\begin{array}{c}\text { Anxiety } \\
\text { syndrome }^{a}\end{array}$ & $\begin{array}{c}\text { Compulsive-obsessive } \\
\text { syndrome }^{b}\end{array}$ & $\begin{array}{l}\text { Somatoform } \\
\text { syndrome }^{c}\end{array}$ & $\begin{array}{l}\text { Eating disorder } \\
\text { syndrome }^{d}\end{array}$ & $\begin{array}{c}\text { Supplementary } \\
\text { items }^{\mathrm{e}}\end{array}$ \\
\hline$A$ & 2.0 & 0.25 & 0 & 0 & 0 & 1.0 \\
\hline B & 2.75 & 1.0 & 0 & 0 & 0 & 1.73 \\
\hline C & 2.5 & 1.0 & 0 & 0 & 0 & 1.82 \\
\hline$D$ & 1.75 & 0.25 & 0 & 0 & 0 & 0.91 \\
\hline
\end{tabular}

a Severity of symptoms: $\geq 0.75$ : suspicious; $\geq 1$ : marginal; $\geq 2$ : modest; $\geq 3$ : severe.

'Severity of symptoms: $\geq 0.67$ : suspicious; $\geq 1$ : marginal; $\geq 2$ : modest; $\geq 3$ : severe.

'Severity of symptoms: $\geq 0.33$ : suspicious; $\geq 0,75$ : marginal; $\geq 1.25$ : modest; $\geq 2.67$ : severe.

${ }^{d}$ Severity of symptoms: $\geq 0.33$ : suspicious; $\geq 0.67$ : marginal; $\geq 1.5$ : modest; $\geq 2.67$ : severe.

eThe supplementary items do not represent an individual construct. They comprise (a) items that can be ascribed to several syndromes and (b) screening items, which can be used

as to guide a more comprehensive search for impairment in the form of specific syndromes. All items attracting a score of $\geq 1$ should be explored more closely (44).

(extremely high functioning)] was also used to rate the women's social, occupational, and psychological functioning $(39,40)$. The Global Assessment of Relational Functioning (41-43) was also estimated (completion: July 2016). All patients gave written informed consent for publication.

\section{CASE PRESENTATIONS}

\section{Patient A}

Patient A (46 years old) reported that she and her family had been attacked by ISIS in August 2014. She became separated from her husband and her four older children. She and her youngest son managed to escape, but the rest of the family was kidnapped. Her daughters spent 14 months in captivity before Patient A was able to ransom them. Patient A, her three daughters and her youngest son were living together in Germany at the time of interview, but her husband and oldest son were still captives of ISIS. This was her main concern. She also felt guilty because it had been she who chose the route home on the day the family was attacked by ISIS fighters. She ruminated and cried a lot. A reported that she was very nervous and agitated on some days, while on others she was totally exhausted and had no energy. Earlier on she had enjoyed having friends come over to her house and cooking for them, but at time of the interview she had no interest in doing things like that and had withdrawn from social events.

In accordance with the psychometric outcomes and the clinical examination the following differential International Classification of Diseases, 10th Revision (ICD-10) (45-48) diagnoses were made:

- adjustment disorder (AD) with mixed anxiety and depression (F42.23);

- target of perceived adverse discrimination and persecution (Z60.5);

- disappearance and death of family members (Z63.4);

- stress, not otherwise classified (Z73.3);

- other personal history of psychological trauma, not otherwise classified (Z91.4).

\section{Patient B}

Patient B was 23 years old on the day of investigation. Like Patient $\mathrm{A}$, she and her family had been attacked and kidnapped by ISIS in
August 2014. Men and women had been separated. Patient B and her three sisters had been part of a group of 100 women displaced to Mosul. There she was forced to live with ISIS combatants, who hit and raped her. In April 2015, her uncle was able to buy her and her sisters' release, but her parents remained in captivity. Patient B said she did not know if they were still alive. She suffered from flashbacks, especially to the maltreatment she had received. As her flashbacks were more intense in the evening, when she went to bed, Patient B slept badly. Patient B also had problems concentrating. She found it very helpful to talk about the things she had experienced and to cry.

In accordance with the psychometric outcomes and the clinical examination the following ICD-10 diagnoses were made:

- AD with mixed anxiety and depression (F42.23);

- target of perceived adverse discrimination and persecution (Z60.5);

- disappearance and death of family members (Z63.4);

- stress, not otherwise classified (Z73.3);

- other personal history of psychological trauma, not otherwise classified (Z91.4).

\section{Patient C}

Patient $\mathrm{C}$ was 40 years old at the time of interview. Her village had also been attacked by ISIS in August 2014. The men and older women were killed on the spot. The younger women were kidnapped and sold. Patient $\mathrm{C}$ reported that she was bought by a high-ranking ISIS military leader in Iraq. She spent most of her time captivity confined to a cell and only sometimes had the company of another Yazidi woman. Patient $\mathrm{C}$ believed that some sort of tranquilizing drug had been added to the captives' food, because she remembered sleeping for abnormally long periods. She was raped several times a week. After nine months she was sold to another man in Mosul, where she was once again sexually abused. In September 2015, she managed to flee with the help of her uncle. Her parents, two of her brothers and her aunt remained captives of ISIS and she did not know if they were still alive. Patient $\mathrm{C}$ reported that she suffered from flashbacks and bad dreams revolving around her family. At the time of the interview, she had talked only to professionals about the things that had happened to her. She had avoided talking to other Yazidi woman in order not to stress them, knowing that they had had similar experiences. She explained that when other women 
started talking about ISIS she would leave the room. She was no longer interested in the things she used to like, such as visiting friends, drawing, and sewing. She said that she had difficulty concentrating, mainly because she was always thinking about her parents. Despite everything, Patient $C$ stated that she was still optimistic and had a positive view of the future. She hoped to be able to start a family.

In accordance with the psychometric outcomes and the clinical examination, the following ICD-10 diagnoses were made:

- AD with mixed anxiety and depression (F42.23);

- other reactions to severe stress (ICD-10: F43.8);

- abuse of a person not otherwise classified (T74.8);

- target of perceived adverse discrimination and persecution (Z60.5);

- disappearance and death of family members (Z63.4);

- stress, not otherwise classified (Z73.3);

- other personal history of psychological trauma, not otherwise classified (Z91.4).

\section{Patient D}

Patient D (34 years old) lived in the refugees' home with her nine children and her husband. She was the only woman whose husband had managed to get to Germany. We saw Patient D three times, because she needed to talk and suffered a lot. Patient $\mathrm{D}$ and her family had lived near Mosul. She was working on a farm when ISIS invaded her village. The terrorists built fortresses around the village, and Patient D and the other inhabitants were forced to grow fruits and vegetables for the ISIS combatants. Patient D was 14 weeks pregnant when the village was invaded and because she was living under constant threat and in fear, she lost the baby. Patient D and her husband hid their two teenage daughters in a hole in the ground to try to protect them from being raped. Everyone in Patient D's family carried a lethal pill that could be used to commit suicide in the event of capture by ISIS. Patient D and her husband had often thought about committing suicide as a family, but in the end, they always decided against it, because of their children and because they hoped to be rescued. Since she came to Germany, Patient D had suffered a multitude of symptoms. She felt depressed and suffered from fear, flashbacks, disordered sleep, and severe headaches. She reported feeling permanently tired and exhausted. She said she had to force herself to do even the smallest things. She would not leave the apartment on her own; she had to be accompanied by a family member at all times. Men with dark beards reminded her of the "disgusting, dirty, and smelly IS [Islamic State] men." When she heard news stories about terror, she was shocked and stopped feeling safe in Germany. At our first meeting, Patient D reported that she got annoyed very quickly and that she often "lost control of herself." It appeared that she sometimes hit her children; this is something she had not done before her experiences with ISIS. She knew that it was seriously wrong but could not help herself. We talked to her about how to cope with anger and fury, and as early as our second session she reported that she was managing to avoid hitting her children when she was irritated.
In accordance with the psychometric outcomes and the clinical examination, the following ICD-10 diagnoses were made:

- AD with mixed anxiety and depression (F42.23);

- target of perceived adverse discrimination and persecution (Z60.5);

- disappearance and death of family members (Z63.4);

- stress, not otherwise classified (Z73.3);

- other personal history of psychological trauma, not otherwise classified (Z91.4).

\section{DISCUSSION}

Refugees are a highly traumatized group of patients who present many clinical challenges, partly because many have experienced trauma related to long civil wars, torture, and ethnic cleansing The diagnosis commonly associated with the initial effects of trauma is PTSD with or without comorbid depression; however, psychosis and neurocognitive disorders are also prevalent (49). Our adult case series both confirms and extends earlier research showing that Yazidi refugee children and adolescents do not just suffer from PTSD but from various other problems such as $\operatorname{ADs}(8,50)$. Patra and Sarkar noted that "adjustment disorder is a diagnostic category characterized by an emotional response to a stressful event. It is a state of subjective distress and emotional disturbance, which arises during the course of adapting to stresses of significant life changes, stressful life events, serious physical illness, or possibility of serious illness. [...] When coping mechanisms fail to ameliorate stress effectively, $\mathrm{AD}$ is precipitated. At a variance from the largely atheoretical model of ICD-10 and DSM-IV-TR, AD is one of the few disorders that take into account the potential cause of the disorder. $\mathrm{AD}$ is a psychiatric diagnosis that falls between normal behavior and the major psychiatric disorders and thus produces taxonomical and diagnostic dilemmas (51)" (52). In contexts such as ours Maercker et al. (53) proposed the application of "a new diagnostic model that describes ADs as particular forms of stress response syndrome, in which intrusions, avoidance of reminders and failure to adapt are the central processes and symptoms" $(53,54)$.

It should also be recognized that survivors of torture have problems that extend beyond PTSD symptoms. There should be recognition of the contextual factors associated with being a (torture) survivor-including being an asylum seeker or refugee and membership of a special ethnic group (55) - and their impact on psychological and social health (4). It is possible that the evaluation process itself may have a beneficial effect on survivors' emotional well-being, e.g., by helping the survivor understand the necessity of telling her story, illuminating the often poorly understood link between ongoing emotional suffering and past torture, strengthening the development of cognitive and emotional control, and healing the wounds of fear, humiliation, marginalization, and mistrust (56). Long-term studies indicate that, in addition to mental disorders, medical disorders such as diabetes and hypertension are also prevalent in traumatized refugees and so it is important that they receive a thorough medical 
evaluation that includes, e.g., the measurement of blood pressure and diabetes testing (49).

When assessing and treating outpatients from a refugee background with multiple or complex trauma (57) both the psychopathological symptoms and positive changes should be addressed (2). For example, it has been shown that traumafocused therapy is not appropriate for all refugee children (58) although the majority of studies of traumatized refugees suggest that trauma-focused therapy reduces trauma-associated symptoms (59). There is evidence that cognitive-behavioral therapy (CBT) (60) and narrative exposure therapy (NET) are appropriate treatments for certain groups of refugees (61). Pharmacotherapy with venlafaxine and sertraline had a similar impact on PTSD symptoms when used in combination with psychotherapy (62). Intervention studies often have methodological limitations such as the absence of a control group, lack of randomization, and use of small samples (63). Furthermore, details of treatment satisfaction or adverse events are not available immediately after therapy or in the medium term. Often inadequate attention is paid to the cultural appropriateness and psychometric properties of interventions and inappropriate measures used to assess their effects. All this means that the findings should be interpreted with caution. That said, the available low-quality evidence suggests that psychological therapies have no immediate effects on posttraumatic symptoms, distress or quality of life in torture survivors although NET and CBT have been shown to produce moderate reductions in distress and PTSD symptoms over the medium term (six months after treatment). To date, there is no evidence on whether reductions in symptoms are associated with improvements in quality of life, participation in community life or social and (family) relationships in the medium term (4).

The availability of culturally sensitive services - for instance, so-called "transcultural psychiatry"-for migrants remains inadequate (64). In this context, one may speculate that the universal construct validity (65) of the diagnoses "PTSD" (66) or "complex PTSD” (67) needs further investigation (68), especially in cultures and populations like the Yazidi. Health services should consider how culture affects the expression of psychological and somatic symptoms and, e.g., avoid drawing a dualistic distinction between somatic and psychological expressions of pain $(26,69)$. Lack of interpreter services can have serious consequences for patients with mental disorders. Trained professional interpreters and bilingual health-care providers have a beneficial effect on patients' satisfaction with care, quality of care and patient outcomes. Training in communication of medical information via an interpreter is still under development $(70,71)$. The difficulties of working with an interpreter highlight the need for both interpreters and (mental) health professionals to receive training in cross-language empathy and should encourage the use of transcultural models of psychotherapy and psychiatry. Some of the difficulties associated with adopting traditional, humanistic models of empathy, which tend to centralize the therapist's perspective within empathic processes when working with interpreters, are still under debate (72).

Future research should address the aforementioned evidence gaps, involve larger samples wherever possible (4) and, among others, explore the correlating neurobiological backgrounds (73). Refugees are generally accepting psychiatric treatment if it is wisely chosen and managed, e.g., through individual evaluation and personalized treatment plans, and it can give them relief from symptoms associated with the massive trauma they have experienced (49).

\section{CONCLUSION}

Refugees are a highly traumatized population, but they do not just suffer from PTSD. ADs are particular forms of stress response syndrome, in which avoidance, intrusions, and failure to adapt are the central processes and symptoms. From a clinical perspective and against the disputable universal construct validity of the PTSD diagnosis, culturally sensitive diagnostic as well as therapeutic services and caregiver or translator education are a prerequisite for achieving improvements in quality of life in this special patient population, which faces multiple problems on many levels and needs to be protected from further damage, e.g., in form of retraumatization or xenophobia. There is also a need for further investigation into the individual-level effects of rape and torture and effects on the historic or systemic/ collective level, e.g., on families and society.

\section{ETHICS STATEMENT}

Only clinical case reports are presented, therefore no accordance with the recommendations of an ethics committee was necessary. All subjects gave written informed consent for publication of this case report and any accompanying information or images.

\section{AUTHOR CONTRIBUTIONS}

IG examined the patients and analyzed the clinical and psychometric data in Germany. JK examined the patients and analyzed the clinical and psychometric data in Iraq. $\mathrm{MN}-\mathrm{H}$ supervised IG, planned the pilot study, and was a major contributor to the writing of the manuscript. All the authors read and approved the final manuscript.

\section{SUPPLEMENTARY MATERIAL}

The Supplementary Material for this article can be found online at http://www.frontiersin.org/article/10.3389/fpsyt.2017.00282/ full\#supplementary-material. 


\section{REFERENCES}

1. Noll-Hussong M, Glaesmer H, Herberger S, Bernardy K, Schonfeldt-Lecuona C, Lukas A, et al. The grapes of war. Somatoform pain disorder and history of early war traumatization in older people. Z Gerontol Geriatr (2012) 45(5):404-10. doi:10.1007/s00391-012-0303-9

2. Teodorescu DS, Siqveland J, Heir T, Hauff E, Wentzel-Larsen T, Lien L. Posttraumatic growth, depressive symptoms, posttraumatic stress symptoms, post-migration stressors and quality of life in multi-traumatized psychiatric outpatients with a refugee background in Norway. Health Qual Life Outcomes (2012) 10:84. doi:10.1186/1477-7525-10-84

3. Buhmann CB. Traumatized refugees: morbidity, treatment and predictors of outcome. Dan Med J (2014) 61(8):B4871.

4. Patel N, Kellezi B, Williams AC. Psychological, social and welfare interventions for psychological health and well-being of torture survivors. Cochrane Database Syst Rev (2014) (11):CD009317. doi:10.1002/14651858. CD009317.pub2

5. Abbott A. The mental-health crisis among migrants. Nature (2016) 538(7624):158-60. doi:10.1038/538158a

6. Fuccaro N. Ethnicity, state formation, and conscription in postcolonial Iraq: the case of the Yazidi Kurds of Jabal Sinjar. Int J Middle East Stud (1997) 29(4):559-80. doi:10.1017/S002074380006520X

7. Fuccaro N. Communalism and the state in Iraq: the Yazidi Kurds, c.1869-1940. Middle East Stud (1999) 35(2):1-26. doi:10.1080/00263209908701264

8. Ceri V, Ozlu-Erkilic Z, Ozer U, Yalcin M, Popow C, Akkaya-Kalayci T. Psychiatric symptoms and disorders among Yazidi children and adolescents immediately after forced migration following ISIS attacks. Neuropsychiatr (2016) 30(3):145-50. doi:10.1007/s40211-016-0195-9

9. Cetorelli V, Sasson I, Shabila N, Burnham G. Mortality and kidnapping estimates for the Yazidi population in the area of Mount Sinjar, Iraq, in August 2014: a retrospective household survey. PLoS Med (2017) 14(5):e1002297. doi:10.1371/journal.pmed.1002297

10. Tekin A, Karadag H, Suleymanoglu M, Tekin M, Kayran Y, Alpak G, et al. Prevalence and gender differences in symptomatology of posttraumatic stress disorder and depression among Iraqi Yazidis displaced into Turkey. Eur J Psychotraumatol (2016) 7:28556. doi:10.3402/ejpt.v7.28556

11. Wilson JP, Drozdek B, Turkovic S. Posttraumatic shame and guilt. Trauma Violence Abuse (2006) 7(2):122-41. doi:10.1177/1524838005285914

12. Pagotto LF, Mendlowicz MV, Coutinho ES, Figueira I, Luz MP, Araujo AX, et al. The impact of posttraumatic symptoms and comorbid mental disorders on the health-related quality of life in treatment-seeking PTSD patients. Compr Psychiatry (2015) 58:68-73. doi:10.1016/j.comppsych.2015.01.002

13. Gillespie CF, Phifer J, Bradley B, Ressler KJ. Risk and resilience: genetic and environmental influences on development of the stress response. Depress Anxiety (2009) 26(11):984-92. doi:10.1002/da.20605

14. Yehuda R, Hoge CW, McFarlane AC, Vermetten E, Lanius RA, Nievergelt CM, et al. Post-traumatic stress disorder. Nat Rev Dis Primers (2015) 1:15057. doi:10.1038/nrdp.2015.57

15. Horn SR, Charney DS, Feder A. Understanding resilience: new approaches for preventing and treating PTSD. Exp Neurol (2016) 284(Pt B):119-32. doi:10.1016/j.expneurol.2016.07.002

16. Mendoza C, Barreto GE, Avila-Rodriguez M, Echeverria V. Role of neuroinflammation and sex hormones in war-related PTSD. Mol Cell Endocrinol (2016) 434:266-77. doi:10.1016/j.mce.2016.05.016

17. Wenk-Ansohn M. Treatment of torture survivors - influences of the exile situation on the course of the traumatic process and therapeutic possibilities. Torture (2007) 17(2):88-95.

18. Mohammadi D. Help for Yazidi survivors of sexual violence. Lancet Psychiatry (2016) 3(5):409-10. doi:10.1016/s2215-0366(16)30004-9

19. Johnson NF, Zheng M, Vorobyeva Y, Gabriel A, Qi H, Velasquez N, et al. New online ecology of adversarial aggregates: ISIS and beyond. Science (2016) 352(6292):1459-63. doi:10.1126/science.aaf0675

20. Wenk-Ansohn M, Gurris N. Intercultural encounters in counselling and psychotherapy - communication with the help of interpreters. Torture (2011) 21(3):182-5.

21. Fischer HF, Tritt K, Klapp BF, Fliege H. [Factor structure and psychometric properties of the ICD-10-Symptom-Rating (ISR) in samples of psychosomatic patients]. Psychother Psychosom Med Psychol (2010) 60(8):307-15. doi:10.1055/s-0029-1214419
22. Fischer HF, Tritt K, Klapp BF, Fliege H. How to compare scores from different depression scales: equating the Patient Health Questionnaire (PHQ) and the ICD-10-symptom rating (ISR) using item response theory. Int J Methods Psychiatr Res (2011) 20(4):203-14. doi:10.1002/mpr.350

23. Tagay S, Arntzen E, Mewes R, Senf W. [Correlation between death of important relatives and posttraumatic stress disorder]. Z Psychosom Med Psychother (2008) 54(2):164-73. doi:10.13109/zptm.2008.54.2.164

24. Tagay S, Zararsiz R, Erim Y, Dullmann S, Schlegl S, Brahler E, et al. [Traumatic events and posttraumatic stress disorder in Turkish-speaking patients in primary care]. Psychother Psychosom Med Psychol (2008) 58(3-4):155-61. doi:10.1055/s-2008-1067357

25. Morina N, Bohme HF, Ajdukovic D, Bogic M, Franciskovic T, Galeazzi GM, et al. The structure of post-traumatic stress symptoms in survivors of war: confirmatory factor analyses of the Impact of Event Scale - revised. J Anxiety Disord (2010) 24(6):606-11. doi:10.1016/j.janxdis.2010.04.001

26. Schubert CC, Punamaki RL. Mental health among torture survivors: cultural background, refugee status and gender. Nord J Psychiatry (2011) 65(3):175-82. doi:10.3109/08039488.2010.514943

27. Morina N, Ehring T, Priebe S. Diagnostic utility of the impact of event scalerevised in two samples of survivors of war. PLoS One (2013) 8(12):e83916. doi:10.1371/journal.pone.0083916

28. Steer RA, Ball R, Ranieri WF, Beck AT. Further evidence for the construct validity of the Beck depression Inventory-II with psychiatric outpatients. Psychol Rep (1997) 80(2):443-6. doi:10.2466/pr0.1997.80.2.443

29. Arnau RC, Meagher MW, Norris MP, Bramson R. Psychometric evaluation of the Beck Depression Inventory-II with primary care medical patients. Health Psychol (2001) 20(2):112-9. doi:10.1037/0278-6133.20.2.112

30. Osman A, Kopper BA, Barrios F, Gutierrez PM, Bagge CL. Reliability and validity of the Beck depression inventory - II with adolescent psychiatric inpatients. Psychol Assess (2004) 16(2):120-32. doi:10.1037/1040-3590. 16.2 .120

31. Osman A, Barrios FX, Gutierrez PM, Williams JE, Bailey J. Psychometric properties of the Beck Depression Inventory-II in nonclinical adolescent samples. J Clin Psychol (2008) 64(1):83-102. doi:10.1002/jclp.20433

32. Segal DL, Coolidge FL, Cahill BS, O'Riley AA. Psychometric properties of the Beck Depression Inventory II (BDI-II) among community-dwelling older adults. Behav Modif (2008) 32(1):3-20. doi:10.1177/0145445507303833

33. Wang YP, Gorenstein C. Psychometric properties of the Beck Depression Inventory-II: a comprehensive review. Rev Bras Psiquiatr (2013) 35(4):416-31. doi:10.1590/1516-4446-2012-1048

34. Subica AM, Fowler JC, Elhai JD, Frueh BC, Sharp C, Kelly EL, et al. Factor structure and diagnostic validity of the Beck Depression Inventory-II with adult clinical inpatients: comparison to a gold-standard diagnostic interview. Psychol Assess (2014) 26(4):1106-15. doi:10.1037/a0036998

35. Cetorelli V, Burnham G, Shabila N. Prevalence of non-communicable diseases and access to health care and medications among Yazidis and other minority groups displaced by ISIS into the Kurdistan Region of Iraq. Confl Health (2017) 11:4. doi:10.1186/s13031-017-0106-0

36. Sheehan DV, Lecrubier Y, Sheehan KH, Amorim P, Janavs J, Weiller E, et al. The Mini-International Neuropsychiatric Interview (M.I.N.I.): the development and validation of a structured diagnostic psychiatric interview for DSM-IV and ICD-10. J Clin Psychiatry (1998) 59(Suppl 20):22-33.

37. Franklin CL, Sheeran T, Zimmerman M. Screening for trauma histories, posttraumatic stress disorder (PTSD), and subthreshold PTSD in psychiatric outpatients. Psychol Assess (2002) 14(4):467-71. doi:10.1037/1040-3590. 14.4.467

38. Elhai JD, Franklin CL, Gray MJ. The SCID PTSD module's trauma screen: validity with two samples in detecting trauma history. Depress Anxiety (2008) 25(9):737-41. doi:10.1002/da.20318

39. Goldman HH, Skodol AE, Lave TR. Revising axis V for DSM-IV: a review of measures of social functioning. Am J Psychiatry (1992) 149(9):1148-56. doi:10.1176/ajp.149.9.1148

40. Sonne C, Carlsson J, Bech P, Vindbjerg E, Mortensen EL, Elklit A. Psychosocial predictors of treatment outcome for trauma-affected refugees. Eur J Psychotraumatol (2016) 7:30907. doi:10.3402/ejpt.v7.30907

41. Committee on the Family of the Group for the Advancement of Psychiatry. Global Assessment of Relational Functioning Scale (GARF):I.Background and rationale. Group for the Advancement of Psychiatry Committee on the Family. Fam Process (1996) 35(2):155-72. doi:10.1111/j.1545-5300.1996.00155.x 
42. Hilsenroth MJ, Ackerman SJ, Blagys MD, Baumann BD, Baity MR, Smith SR, et al. Reliability and validity of DSM-IV axis V. Am J Psychiatry (2000) 157(11): 1858-63. doi:10.1176/appi.ajp.157.11.1858

43. Stein MB, Hilsenroth M, Pinsker-Aspen JH, Primavera L. Validity of DSM-IV axis V global assessment of relational functioning scale: a multimethod assessment. J Nerv Ment Dis (2009) 197(1):50-5. doi:10.1097/NMD. Ob013e3181923cal

44. Tritt K, Heymann FV, Zaudig M, Lynch S, Probst T, Söllner W, et al. The ICD10-Symptom-Rating (ISR) - Brief Description (2013). Available: from: http:// www.iqp-online.de/index.php?mact=Uploads,m0c712,getfile, 1 \&m0c712upload_id $=11 \&$ m0c712returnid $=65$ \&page $=65$

45. Dittmann V, Dilling H. Chapter V (F) of ICD-10: mental, behavioural and developmental disorders - introduction and overview. Pharmacopsychiatry (1990) 23(Suppl 4):137-41. doi:10.1055/s-2007-1014552

46. Okasha A, Seif el Dawla A. Reliability of ICD-10 research criteria: an Arab perspective. Acta Psychiatr Scand (1992) 86(6):484-8. doi:10.1111/ j.1600-0447.1992.tb03302.x

47. Daradkeh TK, Saad A. The reliability and validity of the proposed axis $\mathrm{V}$ (disabilities) of ICD-10. Br J Psychiatry (1994) 165(5):683-5. doi:10.1192/ bjp.165.5.683

48. Mussigbrodt H, Michels R, Malchow CP, Dilling H, Munk-Jorgensen P, Bertelsen A. Use of the ICD-10 classification in psychiatry: an international survey. Psychopathology (2000) 33(2):94-9. doi:10.1159/000029127

49. Kinzie JD. Medical approach to the management of traumatized refugees. J Psychiatr Pract (2016) 22(2):76-83. doi:10.1097/pra.0000000000000135

50. Nasiroglu S, Ceri V. Posttraumatic stress and depression in Yazidi refugees. Neuropsychiatr Dis Treat (2016) 12:2941-8. doi:10.2147/ndt.s119506

51. Strain JJ, Diefenbacher A. The adjustment disorders: the conundrums of the diagnoses. Compr Psychiatry (2008) 49(2):121-30. doi:10.1016/j. comppsych.2007.10.002

52. Patra BN, Sarkar S. Adjustment disorder: current diagnostic status. Indian J Psychol Med (2013) 35(1):4-9. doi:10.4103/0253-7176.112193

53. Maercker A, Einsle F, Kollner V. Adjustment disorders as stress response syndromes: a new diagnostic concept and its exploration in a medical sample. Psychopathology (2007) 40(3):135-46. doi:10.1159/000099290

54. Dobricki M, Komproe IH, de Jong JT, Maercker A. Adjustment disorders after severe life-events in four postconflict settings. Soc Psychiatry Psychiatr Epidemiol (2010) 45(1):39-46. doi:10.1007/s00127-009-0039-z

55. Kizilhan JI. Religious and cultural aspects of psychotherapy in Muslim patients from tradition-oriented societies. Int Rev Psychiatry (2014) 26(3):335-43. doi:10.3109/09540261.2014.899203

56. Gangsei D, Deutsch AC. Psychological evaluation of asylum seekers as a therapeutic process. Torture (2007) 17(2):79-87.

57. Palic S, Zerach G, Shevlin M, Zeligman Z, Elklit A, Solomon Z. Evidence of complex posttraumatic stress disorder (CPTSD) across populations with prolonged trauma of varying interpersonal intensity and ages of exposure. Psychiatry Res (2016) 246:692-9. doi:10.1016/j.psychres.2016.10.062

58. Kinzie JD, Cheng K, Tsai J, Riley C. Traumatized refugee children: the case for individualized diagnosis and treatment. J Nerv Ment Dis (2006) 194(7):534-7. doi:10.1097/01.nmd.0000224946.93376.51

59. Nickerson A, Bryant RA, Silove D, Steel Z. A critical review of psychological treatments of posttraumatic stress disorder in refugees. Clin Psychol Rev (2011) 31(3):399-417. doi:10.1016/j.cpr.2010.10.004

60. Palic S, Elklit A. Psychosocial treatment of posttraumatic stress disorder in adult refugees: a systematic review of prospective treatment outcome studies and a critique. J Affect Disord (2011) 131(1-3):8-23. doi:10.1016/j. jad.2010.07.005

61. Crumlish N, O’Rourke K. A systematic review of treatments for post-traumatic stress disorder among refugees and asylum-seekers. J Nerv Ment Dis (2010) 198(4):237-51. doi:10.1097/NMD.0b013e3181d61258

62. Sonne C, Carlsson J, Bech P, Elklit A, Mortensen EL. Treatment of traumaaffected refugees with venlafaxine versus sertraline combined with psychotherapy - a randomised study. BMC Psychiatry (2016) 16(1):383. doi:10.1186/s12888-016-1081-5

63. Slobodin O, de Jong JT. Mental health interventions for traumatized asylum seekers and refugees: What do we know about their efficacy? Int J Soc Psychiatry (2015) 61(1):17-26. doi:10.1177/0020764014535752

64. Kinzie JD. Immigrants and refugees: the psychiatric perspective. Transcult Psychiatry (2006) 43(4):577-91. doi:10.1177/1363461506070782

65. Rasmussen A, Verkuilen J, Ho E, Fan Y. Posttraumatic stress disorder among refugees: Measurement invariance of Harvard Trauma Questionnaire scores across global regions and response patterns. Psychol Assess (2015) 27(4):1160-70. doi:10.1037/pas0000115

66. McHugh PR, Treisman G. PTSD: a problematic diagnostic category. J Anxiety Disord (2007) 21(2):211-22. doi:10.1016/j.janxdis.2006.09.003

67. Karatzias T, Shevlin M, Fyvie C, Hyland P, Efthymiadou E, Wilson D, et al. An initial psychometric assessment of an ICD-11 based measure of PTSD and complex PTSD (ICD-TQ): evidence of construct validity. J Anxiety Disord (2016) 44:73-9. doi:10.1016/j.janxdis.2016.10.009

68. Friedman MJ, Resick PA, Bryant RA, Strain J, Horowitz M, Spiegel D. Classification of trauma and stressor-related disorders in DSM-5. Depress Anxiety (2011) 28(9):737-49. doi:10.1002/da.20845

69. Kizilhan JI. [Cultural interpretation of pain in family-oriented societies]. Schmerz (2016) 30(4):346-50. doi:10.1007/s00482-016-0127-4

70. Phelan M, Parkman S. How to work with an interpreter. BMJ (1995) 311(7004):555-7. doi:10.1136/bmj.311.7004.555

71. Flores G. The impact of medical interpreter services on the quality of health care: a systematic review. Med Care Res Rev (2005) 62(3):255-99. doi: $10.1177 / 1077558705275416$

72. Pugh MA, Vetere A. Lost in translation: an interpretative phenomenological analysis of mental health professionals' experiences of empathy in clinical work with an interpreter. Psychol Psychother (2009) 82(Pt 3):305-21. doi:10.1348/147608308 ×397059

73. Noll-Hussong M, Otti A, Laeer L, Wohlschlaeger A, Zimmer C, Lahmann C, et al. Aftermath of sexual abuse history on adult patients suffering from chronic functional pain syndromes: an fMRI pilot study. J Psychosom Res (2010) 68(5):483-7. doi:10.1016/j.jpsychores.2010.01.020

Conflict of Interest Statement: The authors declare that the research was conducted in the absence of any commercial or financial relationships that could be construed as a potential conflict of interest.

The reviewer TH and handling editor declared their shared affiliation.

Copyright $\odot 2017$ Gerdau, Kizilhan and Noll-Hussong. This is an open-access article distributed under the terms of the Creative Commons Attribution License (CC BY). The use, distribution or reproduction in other forums is permitted, provided the original author(s) or licensor are credited and that the original publication in this journal is cited, in accordance with accepted academic practice. No use, distribution or reproduction is permitted which does not comply with these terms. 